\title{
IDENTIFIKASI POTENSI PEMBENTUKAN AIR ASAM TAMBANG BATUBARA (PAF /NAF) DENGAN MENGGUNAKAN METODE UJI NAPP (NET ACID PRODUCING POTENTIAL
}

\author{
Baskara Widy Artyanto Putro ${ }^{1}$, Diyan Parwatiningtyas ${ }^{2}$ \\ Dosen Program Studi Teknik Sipil, Fakultas Teknik Sipil \& Perencanaan Universitas Mercubuana \\ Jakarta $^{1}$ \\ Dosen Program Studi Informatika, Fakultas Teknik \& Ilmu Komputer ${ }^{2}$ \\ baskara.putro@gmail.com ${ }^{1}$,diyan_parwatiningtyas@ @unindra.ac.id ${ }^{2}$, diane.tyas@gmail.com²
}

Submitted April 1, 2019; Revised July 15, 2019; Accepted July 28, 2019

\begin{abstract}
Abstrak
Beberapa analisis laboratorium telah banyak dikembangkan di Indonesia dan negara-negara yang melakukan aktifitas tambang, khususnya pertambangan batubara. Tujuan dari analisis ini adalah untuk mengetahui ada dan tidak adanya lapisan tanah yang berpotensi membentuk keasaman. Metode analisis yang paling umum dikenal adalah metode statik dan kinetik. Adapun pengujian kali ini adalah menggunakan metode NAPP (Net Acid Producing Potential), yang mana hasil akhirnya diketahui area tambang tersebut memiliki unsur tanah yang cenderung asam atau tidak. Pelaksanaan investigasi kali ini dilakukan untuk mengetahui tingkat keasaman PAF (Potential Acid Performing) dan NAF (Non Acid Forming), milik perusahaan tambang PT GIE (Globalindo Inti Energy) di wilayah Handil, Muarajawa, Balikpapan, Kalimantan Timur. Dari hasil pengujian dan penyebaran pemetaannya didapatkan bahwa area tambang ini memiliki kandungan unsur tanah yang bersifat NAF (Non Acid Forming), dengan kisaran PH antara 4,65 - 5,75 dan harga NAPP yang bernilai negatif.
\end{abstract}

Kata Kunci : Lahan Tambang Batubara, Pengambilan Sampel dan Uji Laboratorium, Hasil PAF NAF.

\begin{abstract}
Several laboratories tests have been developed in Indonesia and another countries that carry out mining activities, especially coal mining. The purpose of this analysis is to find out the presence and absence of soil layers which have the potential to form acidity. The most commonly known analytical methods are static and kinetic methods. The most commonly known method of analysis is static and kinetic methods. Our test this time are uses the NAPP method (Net Acid Producing Potential).Aand then, from the results of this calculation, was known that the mine area had acidic or not. This time, an investigation was conducted to determine the acidity of PAF (Potential Acid Forming) and NAF (Non Acid Forming), which is owned by the mining company PT GIE (Globalindo Inti Energy) at the Handil, Muarajawa, Balikpapan, East Kalimantan regions. From the results of tested and mapped, it was found that this mining area had NAF (Non Acid Forming) soil content, with a PH range between 4.65 - 5.75 and had a negative NAPP price.
\end{abstract}

Keywords : Coal Mining Land, Sampling and Laboratory Tested, NAPP,PAF NAF result.

\section{PENDAHULUAN}

Beberapa analisis laboratorium telah banyak dikembangkan di Indonesia dan negara-negara yang melakukan aktifitas tambang, khususnya pertambangan batu bara. Tujuan dari analisis tanah tambang ini adalah untuk mengetahui sifat dari lapisan tanah dari lokasi pertambangan sebelum melakukan eksplorasi penambangan. Ini dilakukan untuk mengetahui ada dan tidak adanya lapisan tanah yang berpotensi membentuk keasaman. Metode analisis yang palingumum dikenal adalah metode statik 
dan kinetik. Adapun pengujian kali ini adalah menggunakan metode NAPP (Net Acid Producing Potential).

Di Indonesia, analisa statik NAPP adalah yang paling banyak dikenali baik oleh pemerintah, laboratorium independent dan perusahaan pertambangan itu sendiri. Pada metode ini potensi keasaman maksimum dari tanah tambang yang dianalisis ditentukan berdasarkan jumlah total sulfur sebesar $1 \%$ pada batuan sebanyak 1 ton akan menghasilkan asam sulfat sebanyak $30,62 \mathrm{~kg}$ yang membutuhkan $31,25 \mathrm{~kg}$ $\mathrm{CaCo}_{3}$ untuk menetralkannya. [3]. Pelaksanaan investigasi kali ini dilakukan pengujian NAPP di area tambang batubara untuk mengetahui tingkat keasaman PAF dan NAF, milik perusahaan PT GIE (Globalindo Inti Energy) di wilayah Handil, Muarajawa, Balikpapan, Kalimantan Timur.

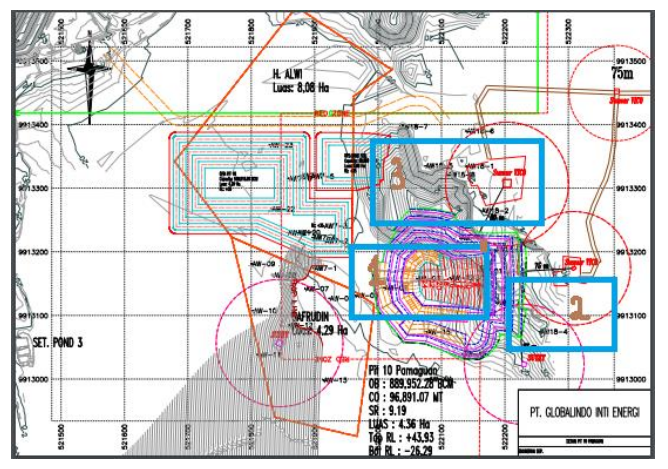

\section{Gambar 1. Lokasi Area Identifikasi PAF dan NAF di PT GIE Handil, Kalimantan Timur}

\section{METODE PENELITIAN}

\section{Lokasi dan Waktu Penelitian}

Penelitian dilakukan di Jakarta dan Handil Kalimantan Timur, dengan mengajak kerjasama dengan PT GIE (Globalindo Inti Energy) selama enam bulan, periode tahun 2018 yang bersifat Research and Development $(R \& D)$, dengan menerapkan beberapa metode antara lain :

1. Metode penentuan geokimia batuan menggunakan Uji Statik metode NAPP. Metode NAPP adalah metode pencegahan pembentukan AAT melalui identifikasi dari karakteristik batuan yang mengandung mineral sulfida yang menitikberatkan pada analisis potensi keasaman tanah/batuan daerah tambang, yaitu berupa berat $\mathrm{kg} \mathrm{H} 2 \mathrm{SO} 4$ tiap ton [4] dan [5].

2. Parameter acuan untuk mengetahui potensi PAF (Potensial Acid Forming) atau NAF (Non Acid Forming) pada metode NAPP berdasarkan pada perbandingan antara nilai NAPP dan NAG $\mathrm{pH}$ (Net Acid Generation), $\quad$ yang penggolongannya terlihat pada tabel 1 dibawah ini. Tahapan metodologi pemodelan sebaran PAF dan NAF dapat dilihat pada gambar 2.

Tabel 1. Kriteria Batuan PAF dan NAF [5]

\begin{tabular}{cc}
\hline Parameter & Kriteria \\
\hline NAPP $\leq 0$ dan NAGpH $\geq 4,5$ & NAF \\
NAPP $>0$ dan NAGpH $<4,5$ & PAF \\
NAPP $>0$ dan NAGpH $>4,5$ & Uncertain \\
Atau & \\
NAPP $\leq 0$ dan $\mathrm{NAGpH}<4,5$ & \\
\hline
\end{tabular}




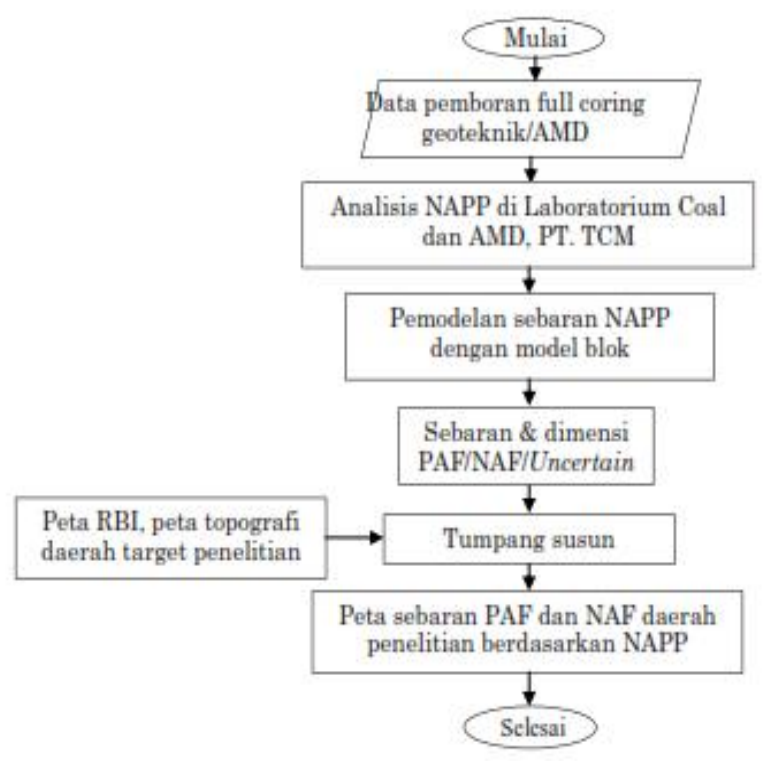

Gambar 2. Diagram Alir Metodologi Pemodelan sebaran PAF NAF di Area Investigasi

\section{Pengambilan Sampel}

Sampel yang digunakan dalam analisis berasal dari pemboran full coring pemboran AMD (Acid Mine Drainage) yang berupa batuan inti (core) dari 6 titik bor [10]. Sampel diambil ratarata tiap interval kedalaman 0,5-1,6 meter dari titik bor yang pemilihannya dipengaruhi oleh jenis batuan dan kedalaman lubang pemboran. Pengambilan interval disesuaikan dengan kebutuhan data yang didasarkan pada perubahan litologi [7],[8]. Pendeskripsian batuan dilakukan secara langsung setelah core keluar dari core barrel dan dilakukan logging dengan cepat pada sampel core. Selanjutnya, sampel disegel, dilaminasi dan dibungkus dengan kertas alumunium foil sehingga tidak mengalami kontaminasi dengan udara, terjaga suhu dan kelembabannya. Setelah pembungkusan dan penyegelan sampel dibawa ke laboratorium. [6]. Kenampakan sampel dari lapangan yang terbungkus dan tersegel dapat dilihat pada Gambar 3.

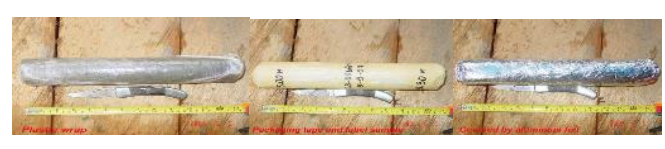

\section{Gambar 3. Sampel Tanah yang Tersegel dan Akan Diuji PAF NAF}

Jenis batuan yang diambil berupa batuan sedimen, antara lain: batulempung, batulanau, dan batupasir. Sampel-sampel tersebut digunakan sebagai database batuan untuk penghitungan nilai NAPP. Selanjutnya, nilai NAPP lapisan $\mathrm{PAF} / \mathrm{NAF}$ digunakan sebagai data masukkan untuk pemodelan metode model blok dengan software surpac vision.

\section{Analisis Uji Statistik}

Menurut Marthen (2013) [5] dan Ian dkk, [4], bahwa analisis metode NAPP terdiri dari analisis \% TS, NAG pH, dan ANC. \% TS merupakan jumlah kandungan sulfur (organik/anorganik) dalam sampel batuan yang mengindikasikan jumlah asam sulfat yang terbentuk pada proses oksidasi dan reduksi dalam sampel. Prinsip kerja analisis TS yaitu dengan memijarkan sampel mencapai suhu $\pm 1.250{ }^{\circ} \mathrm{C}$ ke dalam furnace type Lecco S-144DR. Oksida-oksida sulfur yang dihasilkan dari proses pemijaran ditangkap oleh sensor pendeteksi sulfur untuk mengetahui \% sulfur. [9]. NAG merupakan analisis jumlah potensi keasaman yang terbentuk setelah terjadi oksidasi pirit dalam tanah/batuan tambang. Reaksi yang terjadi dalam NAG antara lain, reaksi keasaman dan penetralan dengan hasil akhir reaksi oksidasi adalah nilai NAG $\mathrm{pH}$ yang menunjukkan indikasi sifat keasaman atau kebasaan dari sampel batuan. Hasil analisis NAG pH di bawah 4,5 akan dilakukan tahap penitaran (titrasi) dengan larutan basa $\mathrm{NaOH} \mathrm{pH}$ 4,5 dan 
dilanjutkan dengan $\mathrm{pH} \mathrm{7,} \mathrm{jumlah} \mathrm{larutan}$ penitaran berbanding lurus dengan jumlah $p$ otensi asam dalam sampel analisis. ANC adalah metode penetapan jumlah mineral penetral (misalnya mineral karbonat, CO3) dalam batuan yang dapat bereaksi dengan mineral pengasam (misalnya mineral sulfida, SO 4). Selain itu, ANC bermanfaat untuk menentukan kemampuan sampel dalam menetralkan asam yang terkandung dalam sampel. Jumlah nilai ANC akan berpengaruh terhadap sifat alkalinitas sampel. Prinsip kerja penentuan ANC yaitu, mereaksikan kandungan mineral penetral (CO3) dalam sampel dengan penambahan asam $(\mathrm{HCl})$ berlebih melalui penitrasian dengan basa $(\mathrm{NaOH})$ hingga $\mathrm{pH} 7$.

\section{Analisis Metode Model Blok}

Pemodelan menggunakan metode model blok dengan batuan tool surpac vision. Model blok adalah data yang diinterpretasikan secara visual dalam bentuk kubus tiga dimensi. Dalam kubus tersebut terdapat kotak-kotak kecil yang digunakan sebagai acuan perhitungan luasan daerah pengaruh lapisan. Metode ini sering digunakan dalam perhitungan cadangan batubara yang didasarkan pada NNP (Neighborhood Nearest Point), IDW (Inverse Distance Weighting), dan krigging yang pemilihannya dipengaruhi jumlah data titik bor yang digunakan sebagai interpolasi. Pada pengerjaan geoteknik ini, interpolasi data titik bor menggunkan NNP yang disebabkan jumlah titik bor yang terbatas jumlahnya, yaitu 6 titik bor. Luas blok tiap sisi blok disesuaikan dengan pola sebaran nilai pengaruh dari NAPP yang telah diketahui dari hasil analisis laboratorium. Nilai NAPP untuk lapisan PAF $>0$ dan NAF $<0$ (Tabel 1). Sebaran tiap nilai NAPP dari sampel di interpolasi sehingga mendapatkan nilai pengaruh dengan variasi NAPP yang berkorelasi dengan jenis batuan. Lapisan bawah permukaan yang diwakili oleh satuan batuan geologi Formasi Balikpapan menjadi batas bawah model blok dan menjadi penentu sebaran NAPP dalam tiap batuan. Data-data pendukung yang digunakan sebagai database adalah data bor, nilai NAPP, jenis batuan, topografi permukaan dan bawah permukaan.

\section{HASIL DAN PEMBAHASAN}

Hasil dari analisis metode NAPP di laboratorium mengindikasikan, bahwa batuan lanau dan Clay yang mendominasi lapisan NAF (Non Acid Forming) dengan kisaran NAG pH 4,65- 5,75 dan NAPP antara $-7,623$ hingga $-2,23$. Pada area tambang batubara yang diidentifikasi, tidak mengindikasikan adanya sebaran PAF (Potential Acid Forming).

Lapisan NAF dalam mayoritas sampel titik bor mempunyai ketebalan antara 1,95-40 meter. Meskipun dijumpai lapisan yang sangat tebal (> 40 meter), namun penyebarannya hanya terfokus pada lokasilokasi yang mempunyai karaketeristik batuan tertentu, seperti sekitar lapisan batubara. Secara keseluruhan lapisan NAF lebih mendominasi dari pada lapisan PAF. Selain itu, pada area ini tidak diketemukannya lapisan uncertain pada lapisan alluvial. 
Tabel 2. Tabel Karakteristik Lapisan NAF daerah Tambang Batubara PT GIE

\begin{tabular}{|c|c|c|c|c|c|}
\hline Titik Bor & $\begin{array}{l}\text { Dominasi } \\
\text { Batuan }\end{array}$ & $\begin{array}{l}\text { Tebal } \\
\text { Lapisan } \\
(\mathrm{m})\end{array}$ & NAPP & $\begin{array}{l}\text { NAG } \\
(\mathbf{p H})\end{array}$ & Kriteria \\
\hline $\begin{array}{l}\text { Geotek_02 } \\
\text { (Lintasan } \\
\text { 2) }\end{array}$ & $\begin{array}{l}\text { Batuan } \\
\text { Lempung, } \\
\text { Batuan } \\
\text { Pasir, Clay }\end{array}$ & $25-25,5$ & $-7,623$ & 4,65 & NAF \\
\hline $\begin{array}{l}\text { Geotek_02 } \\
\text { (Lintasan } \\
\text { 2) }\end{array}$ & $\begin{array}{l}\text { Batuan } \\
\text { Lempung, } \\
\text { Batuan } \\
\text { Pasir, Clay }\end{array}$ & $15-15,5$ & $-2,23$ & 5,75 & NAF \\
\hline $\begin{array}{l}\text { Geotek_03 } \\
\text { (Lintasan } \\
\text { 1) }\end{array}$ & $\begin{array}{l}\text { Batuan } \\
\text { Lempung, } \\
\text { Batuan } \\
\text { Pasir, Clay }\end{array}$ & $\begin{array}{l}17,55 \\
18,05\end{array}$ & $-6,337$ & 5,4 & NAF \\
\hline $\begin{array}{l}\text { Geotek_03 } \\
\text { (Lintasan } \\
\text { 1) }\end{array}$ & $\begin{array}{l}\text { Batuan } \\
\text { Lempung, } \\
\text { Batuan } \\
\text { Pasir, Clay }\end{array}$ & $\begin{array}{l}19,5 \\
20,00\end{array}$ & $-6,120$ & 5,6 & NAF \\
\hline $\begin{array}{l}\text { Geotek_04 } \\
\text { (Lintasan } \\
\text { 3) }\end{array}$ & $\begin{array}{l}\text { Batuan } \\
\text { Lempung, } \\
\text { Batuan } \\
\text { Pasir, Clay }\end{array}$ & $\begin{array}{l}15,00 \\
15,5\end{array}$ & $-7,246$ & 4,82 & NAF \\
\hline $\begin{array}{l}\text { Geotek_04 } \\
\text { (Lintasan } \\
\text { 3) }\end{array}$ & $\begin{array}{l}\text { Batuan } \\
\text { Lempung, } \\
\text { Batuan } \\
\text { Pasir, Clay }\end{array}$ & $\begin{array}{l}25,00 \\
25,5\end{array}$ & $-5,634$ & 5,73 & NAF \\
\hline
\end{tabular}

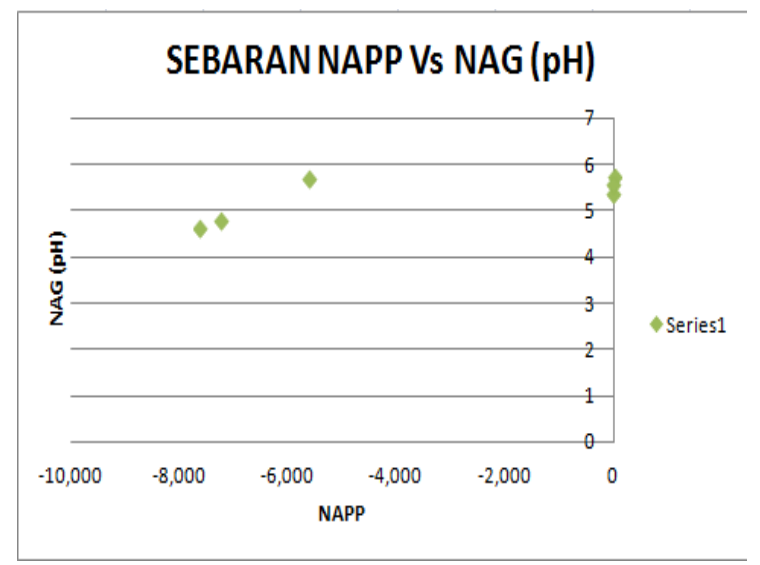

Gambar 4. Diagram Sebaran NAPP dan NAG (pH)

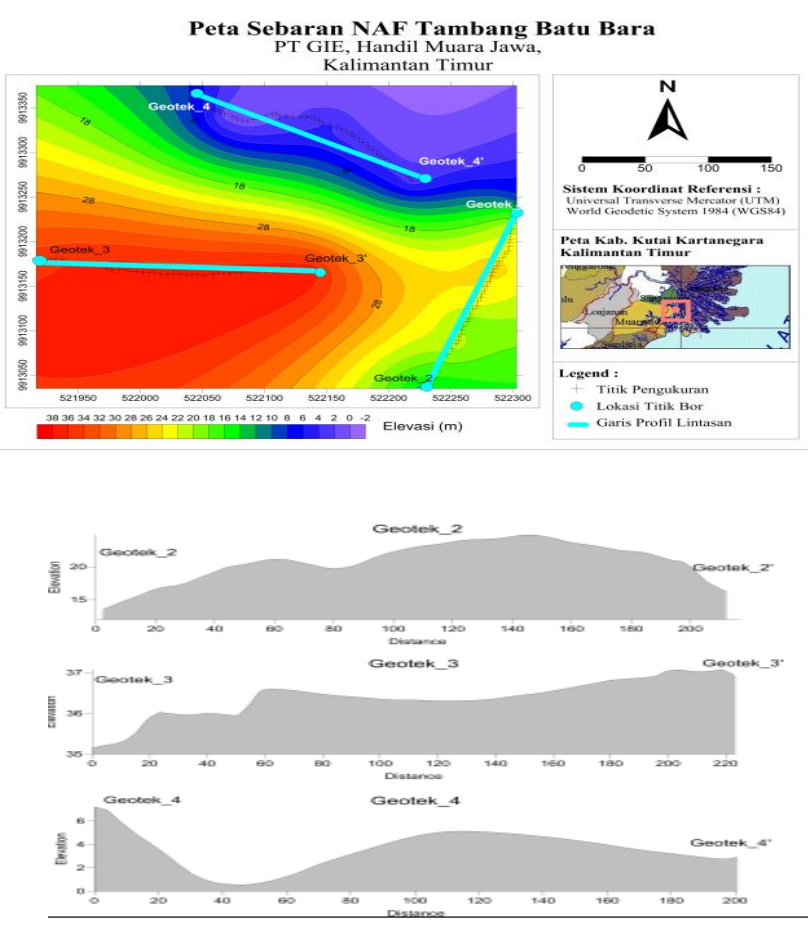

Gambar 5. Peta Sebaran NAF di Area PT. GIE Handil, Kalimantan Timur

\section{SIMPULAN}

Berdasarkan hasil pembahasan diatas dapat diperoleh beberapa kesimpulan, antara lain:

1. Hasil dari analisis metode NAPP di laboratorium mengindikasikan, bahwa batuan lanau dan Clay yang mendominasi lapisan NAF (Non Acid Forming) dengan kisaran NAG $\mathrm{pH}$ 4,65- 5,75 dan NAPP antara $-7,623$ hingga $-2,23$.

2. Pada area tambang batubara yang diidentifikasi, tidak mengindikasikan adanya sebaran PAF (Potential Acid Forming) yang berdampingan dengan titik bor.

\section{UCAPAN TERIMAKASIH}

Pada kesempatan ini, Penulis mengucapkan terimakasih yang sebesarbesarnya kepada team konsultan PT. Putra Cipta Jaya dan PT. Globalindo Inti Energi yang telah memberikan bantuan berupa 
kerjasama penelitian dan proyek pengerjaan identifikasi sebaran PAF NAF di area pertambangan setempat kepada Penulis. Semoga di kesempatan yang akan datang, kerjasama dan solidaritas yang dicapai senantiasa dapat ditingkatkan lebih baik lagi dibandingkan dari masa-masa sebelumnya.

\section{DAFTAR PUSTAKA}

[1] Atkinson, T., 1983, Surface Mining and Quarrying, Proc. 2nd Intl. Surface Mining and Quarrying Symposium, Institution of Mining and Metallurgy Bristol, U.K.

[2] Costello, C., 2003, Acid Mine Drainage: Innovative Treatment Technologies, U.S. Environment Protection Agency Report, Report for Office of Solid Waste and Emergency Response Technology Innovation Office, Washington, USA, p. 46.

[3] Gautama, R.S., 2012, Pengelolaan Air Asam Tambang, Bimbingan Teknis Reklamasi dan Pascatambang Pada Kegiatan Pertambangan Mineral dan Batubara, Ditjen Mineral dan Batubara, KESDM, Yogyakarta.

[4] Ian, R., Taylor, J., Pape, S., Yardi, R., dan Bennett, J., 2007, Managing Acid and Metalliferous Drainage, Report for Departement of Industry Tourism and Resources, Australian Government, Australia, p. 95.
[5] Marthen M., 2013, Identifikasi Potensi Pembentukan Air Asam Tambang, NAPP VS NTAPP, Buku Panduan, PT. Trubanindo Coal Mining, Kutai Barat, Kalimantan Timur.

[6] Polawan Malim Sutan. S, 2017, Identifikasi Air Asam Tambang Melalui Metode Uji Statik Pada Tambang Batubara, Jurnal "Gerbang Etam” Balitbangda Kabupaten Kukar Vol. 11 No.1 Tahun 2017.

[7] Sobek, A.A, Schuller, W.A., Freeman, J.R. Smith R.M 1978. Field and laboratory Methods Applicable to Overburden and Minesoils. EPA 600/2-78-054.

[8] Skousen, J.G et.al., 1987, A Review of Procedures for Surface Mining and Reclamation in Area with AcidProducing Materials. Bekerjasama dengan The West Virginia Surface Mine Drainage Task Force-The West Virginia University dan The West Mining and Reclamation Association, West Virginia U.S.A.

[9] Suits \& Arthur. 2000, Sulfur Diagenesis and Partitioning in Holocene Peru Shelf and Upper Slope Sediments. Chemical Geology, Isotope Geoscience, Vol 163. Elsevier.

[10] Stewart, Warwick, 2005, Development of Acid Rock Drainage Prediction Methodhologies for Goal Mine Wastes. Ian Wark Research Institute University of South Australia, Australia. 